\title{
Welsh-language prestige in adolescents: attitudes in the heartlands
}

Price, Abigail; Tamburelli, Marco

\section{International Journal of Applied Linguistics}

DOI:

10.1111/ijal.12274

Published: 01/07/2020

Peer reviewed version

Cyswllt i'r cyhoeddiad / Link to publication

Dyfyniad o'r fersiwn a gyhoeddwyd / Citation for published version (APA):

Price, A., \& Tamburelli, M. (2020). Welsh-language prestige in adolescents: attitudes in the heartlands. International Journal of Applied Linguistics, 30(2), 195-213.

https://doi.org/10.1111/ijal.12274

Hawliau Cyffredinol / General rights

Copyright and moral rights for the publications made accessible in the public portal are retained by the authors and/or other copyright owners and it is a condition of accessing publications that users recognise and abide by the legal requirements associated with these rights.

- Users may download and print one copy of any publication from the public portal for the purpose of private study or research.

- You may not further distribute the material or use it for any profit-making activity or commercial gain

- You may freely distribute the URL identifying the publication in the public portal ?

Take down policy

If you believe that this document breaches copyright please contact us providing details, and we will remove access to the work immediately and investigate your claim. 


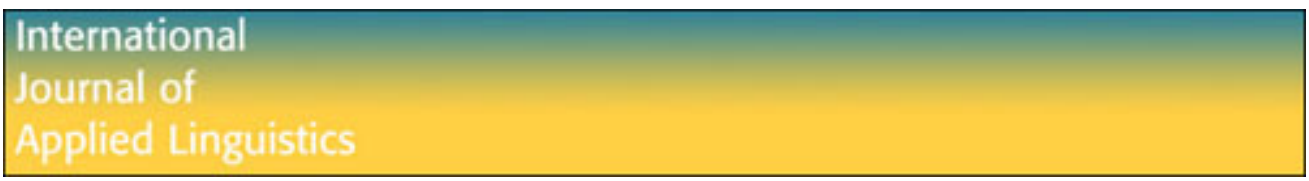

Welsh-language prestige in adolescents: attitudes in the heartlands

\begin{tabular}{|r|l|}
\hline Journal: & International Journal of Applied Linguistics \\
\hline Manuscript ID & InJAL-17-151-Art.R2 \\
\hline Manuscript Type: & Original Article \\
\hline Keywords: & $\begin{array}{l}\text { language attitudes, minority languages, adolescents, language \& gender, } \\
\text { Welsh }\end{array}$ \\
\hline \multicolumn{2}{|l}{} \\
\hline
\end{tabular}

\section{SCHOLARONE ${ }^{m}$ \\ Manuscripts}




\title{
Welsh-language prestige in adolescents: attitudes in the heartlands
}

\begin{abstract}
We investigate covert attitudes towards Welsh and English as a medium of informal communication among L1 Welsh-English bilingual adolescents. We collected quantitative data using an adaptation of the Matched-Guise technique, testing measures of social attractiveness within youth culture via an indirect method. A total of thirty-five adolescents took part in this study. We perform a 2 (language: Welsh / English) $\times 2$ (register: high / low) $\times 2$ (participant gender: male / female) mixed-design ANOVA, with participant gender as the between-subjects variable. Results show English rated more favourably than Welsh overall, with female participants rating Welsh guises significantly more highly than males. This lends empirical support to the perception of Welsh as a language of school and officialdom while English fulfils the language of leisure.
\end{abstract}

\section{Keywords}

Language attitudes, minority languages, adolescents, gender, Welsh 


\section{Introduction}

Throughout the $20^{\text {th }}$ Century, Welsh language activism called for political and attitudinal change at local and Government level, consequently gaining official recognition for the Welsh language in formal domains (Welsh Language Act, 1967; Welsh Language Act, 1993). Today, improvements are evidenced by the increased demand for public-sector provision, acquisition planning and curricular inclusion of Welsh (Jones and Martin-Jones, 2004; Jones, 1990). The education system plays a crucial role as a main agent of Welsh language reproduction and transmission throughout Wales (Kenesei, 2009; May, 2000). Present-day maintenance of Welsh seems to be politically secure (Baker, 2003), as perceived high-prestige and economic benefits have been generated for the language through its introduction in institutional domains (Hodges, 2012). However, while the Welsh language now enjoys relatively heightened prestige compared to other cases of minority languages (e.g. Cormack, 2007), the onus of its maintenance tends to lie primarily with language planners and policy makers, raising well-known issues that result from over-reliance on top-down practices (e.g. Gruffudd, 2000; Hodges, 2011; Ó Riagáin et al., 2008; Williams, 1992).

One such issue is that the stated and overt language policies of bilingual environments often differ considerably from practical-level realisation (Schiffman, 1996). This can often mean that while one variety finds favour at the formalised policy level, speakers may commonly employ the apparently 'disfavoured' variety in cultural practice (Sophocleous, 2011:267). Therefore, while bilingual education may offer a necessary language planning model for the increase of speaker numbers (Baker, 2003), the high level of input afforded through the minority language education system does not necessarily equate to high levels of language use amongst speakers (Thomas \& Gathercole, 2009). The Welsh case provides a potential example of this discrepancy, and it has been demonstrated that despite educational channels providing daily input in Welsh, the language is not necessarily used as a 
conversational medium between Welsh speaking children, both in informal domains and in the absence of an authority figure (Gathercole \& Thomas, 2009; Price \& Tamburelli, 2016; Thomas \& Roberts, 2011). While being used for in-class work and in the presence of an authority figure, Welsh is not necessarily perceived as an appropriate medium of communication in the conversational domains (Price \& Tamburelli, 2016). Welsh-speaking children have been observed as 'unwilling' to communicate in Welsh in low-domain interactions (see Thomas \& Roberts, 2011), increasing the previously reported trend for Welsh-educated pupils to avoid the use of Welsh in informal out-of-school communication (Baker, 2003). These trends are further evident in Thomas, Apollonia and Lewis (2014); language attitudes of L2 children from English-dominant homes were elicited, demonstrating that L2 English-dominant children displayed greater favourability towards English than towards Welsh. Similar phenomena have also been observed in other immersion contexts. For example, the informal practices of Catalan teenagers have been reported as 'lagging behind' (Wieland, 2009), with pupils using the minority language for in-class exercises while conducting wider community and peer-to-peer social interaction through the majority language (Cenoz 2008). Similarly, L2 Welsh-educated children have been reported to show greater likelihood to revert to their L1 in everyday social interactions (Thomas \& Roberts 2011; Thomas et al., 2012; Price \&Tamburelli, 2016).

\section{This pattern of retroversion has also been shown to be affected by gender. The} tendency to use English is particularly evident in primary-aged boys, and specifically pronounced in L2 speakers (Thomas et al., 2012). Specifically, Thomas and Roberts (2011) report that in-class peer-to-peer interaction is through the medium of Welsh $69.4 \%$ for young boys, contrasted with $91.7 \%$ for girls. In younger and adolescent speakers, female participants have proven to be markedly more active users of the language than males, particularly when discussing academic topics (Hodges, 2009; Morris, 2010). Research on L1 
and L2 Welsh speaking adults in Higher Education Institutions (Laugharne, 2007) suggests that this gender-gap transcends beyond school, with male participants showing more favourability towards English than their female counterparts.

\section{Methodological issues: gender preferences and overt vs covert attitudes}

Despite evident gender-related trends becoming increasingly apparent in the literature on Welsh attitudes, researchers have suggested that this lack of willingness to apply Welsh is likely due to low-levels of speaker confidence and perceived language competence/ proficiency (Morris, 2014; Thomas et al., 2014; Thomas \& Roberts, 2011). Pointedly, Laugharne (2007) highlights the fact that these patterns are driven by self-reported speaker competency, with Higher Education Welsh-home speakers self-reporting higher levels of proficiency, and consequently greater positivity towards Welsh. Morris (2014) also reports positive conscious attitudes as expressed by sixth form ${ }^{1}$ students towards the Welsh language, correlating participant confidence with increased use of Welsh. It has also been suggested that use of Welsh may be curbed by speakers' heightened sensitivity to English as the dominant language of social inclusivity and mutual understanding (Gathercole, 2007; Thomas et al., 2014. See Hickey, 2007 for a similar analysis of the Irish situation). Additionally, some speakers have shown a greater awareness of the iconic value of Welsh rather than viewing it as a day-to-day medium (Coupland, Bishop, Williams, Evans \& Garrett, 2005).

Although there is some evidence that confidence and proficiency levels play a role in the favourable view towards Welsh (Coupland et al. 2005), the lack of Welsh engagement among males as exemplified in the literature cannot be wholly attributed to low speaker confidence without a thorough exploration of underlying speaker attitudes. However, the

\footnotetext{
${ }^{1}$ Sixth form refers to the non-compulsory final years of high school, comparable to twelfth grade in the American schooling system.
} 
present study will expand on previous findings with reference to speaker attitudes; by doing this, we will widen the scope of understanding behind speakers' language preference. At present, much of the existing attitudinal research relies on self-reports and direct methodologies (Coupland et al., 2005; Laugharne, 2007; Morris, 2014). In an attempt to tackle this issue, Price and Tamburelli (2016) investigated covert attitudes among male adolescents through the focus group methodology, thus providing an insight into in-group language attitudes. Their study suggests that the reason for a lack of engagement with Welsh is at least partly due to the covert linguistic attitudes of adolescent speakers. Specifically, Price and Tamburelli (2016) suggest that Welsh is becoming increasingly associated with heightened overt prestige - namely school system formalities, high-domain transmission in education, higher education and public sector roles - while English fulfils the covertly prestigious role amongst teenage speakers. It is this covertly prestigious form which sets the tone for language change, with potentially negative impacts filtering down to the attitudes that surround the Welsh language in general and its perceived domains of use in particular.

The identified reluctance to use Welsh in peer-to-peer communication (Thomas \& Roberts, 2011; Thomas et al, 2014) may partly be influenced by such an association of Welsh with the formal domains. This association would then explain the gender patterns evident in the literature. Given the cross-linguistic tendency for female speakers to display favourable attitudes towards highly prestigious forms 'from above' (i.e. perpetuated by formal institutions) and male speakers to show favour towards vernacular varieties (Bilaniuk, 2003; Eckert, 1989, 1990, 1998), it is perhaps unsurprising that Welsh should be favoured by females. On this view, the reasons behind the reported lack of Welsh engagement are closely tied to well-known gender patterns reported for other linguistic situations, such as the research carried out in Ukraine (Bilaniuk, 2003) which demonstrates women displaying greater favourability towards the more socially acceptable H(igh) language, namely English, 
due to the association of English with opportunity for social advancement. Similarly, female secondary school students in Guangzhou, China (see Wang \& Ladegaard, 2008) showed preferential attitude to the use of the prestigious variety Putonghua $(\mathrm{H})$ over Cantonese $(\mathrm{L})$.

\section{Eliciting covert and overt attitudes}

There is a discrepancy in the literature between previous self-report studies in Wales demonstrating outwardly positive attitudes towards Welsh (Lyon \& Ellis, 1991; Coupland et al 2005; Laugharne, 2007; Morris, 2014) and negative attitudes towards Welsh evident in more recent work (Price \& Tamburelli, 2016). Within the Irish context, Irish-medium students self-report positive attitudes towards Irish yet turn away from the language in peerto-peer interaction (Ó Duibhir, 2009: 114). Similarly within the Gaelic context, overtly positive language attitudes co-exist with patterns of falling use (Cochran, 2008; Müller, 2006). As suggested by these findings, language attitude data obtained through self-reports have limitations (see Fasold, 1984) and do not predict speakers' language use. Such explicit, overt attitudes elicited from direct methods are held at the conscious level, deliberately formed and easier to self-report. These overt attitudes often reflect established institutional and policy norms (Maegaard, 2005) rather than reflecting inner-held beliefs. In order to fully explore the reported trends of speakers reluctant to communicate through the medium of Welsh (Thomas \& Roberts, 2011; Thomas et al. 2014), the present investigation will elicit covert attitudes of the speakers, rather than overt attitudes as commonly explored in previous literature. By doing so, we fill this critical lacuna in the literature and, as covert attitudes play a greater role in influencing speaker behaviour 'on the ground' (Kristiansen, Harwood \& Giles 1991; Maegaard 2005, 2010), we will provide a new approach in the Welsh context. Indeed, covert attitudes have been elicited as a means to uncover the sociolinguistic position of Spanish and Catalan in Catalonia (Woolard \& Gahng, 1990) and Sicilian in Sicily 
(Ruffino, 2006). These covert attitudes are obtained via indirect methods which elicit attitudinal patterns that tally closely with changes in language use (Maegaard, 2005). Social attitude and behavioural disposition have played an important role in predicting and explaining human behaviour (Ajzen, 1991), and as such can inform aspects of linguistic behaviour and ultimately of linguistic vitality. Attitudes develop from beliefs speakers hold about an attitude object (Ajzen, 1991); as such, speaker attitudes must be elicited in order to aid our explanation of speaker choice in choosing of a particular linguistic variety.

Considering the distinction between direct and indirect methods, we infer that previous attitudinal studies in Wales have provided evidence for speakers' overt - rather than covert language attitudes (e.g Coupland et al. 2005), hence explaining the discrepancy in the literature between previously positive self-reports (Coupland et al 2005; Laugharne, 2007) and the negative attitudes more recently recorded (Price \& Tamburelli, 2016).

Crucially, research demonstrates that attitudes differ greatly depending on whether they have been elicited directly or indirectly (i.e. Maegaard, 2005). As highlighted by McKenzie and Gilmore (2017), the results of studies of unconsciously held evaluations confirm the divergence between implicitly and explicitly held attitudes. The use of indirect methods for eliciting covert attitudes is particularly important in investigating the linguistic behavior of adolescent speakers, as adolescence provides a pivotal shift in the orientation of speakers' linguistic attitudes, whereby they move away from family influence and towards peer-group influence (Harmer, 1991; Taylor, 2000; Dörnyei, 2001). However, at present there is a lack of quantitative data on the attitudes of speakers who have access to Welsh beyond the classroom, namely L1 community speakers. As discussed, the majority of research pertains to L2 speakers. In these studies, weakened association of Welsh among speakers has been explained by factors such as lacking opportunity for use, lacking confidence and lacking relevance of the Welsh language (Coupland et al., 2005; Gathercole, 2007; Hickey, 2007; 
Thomas et al., 2014). While it is accepted that those who speak Welsh at home have a greater disposition to use Welsh outside of the home (Coupland et al., 2005; Morris, 2014) and a clear relationship exists between home-supported language input and the speaker ability with the minority language (Gathercole 2002; Rhys and Thomas, 2013), family language and language proficiency cannot be used to gauge covert attitudes or willingness to communicate through Welsh. If this were the case, then we would expect L1 speakers to show markedly different associations with Welsh than L2 speakers, as L1 speakers are unlikely to lack in confidence, opportunities or language relevance as much as L2 speakers. If instead our study provides evidence of weakened association towards Welsh among L1 speakers, we would have evidence that there is an additional attitudinal factor contributing to preference to English among L1 speakers, as presently observed in L2 speakers. In order to further investigate speakers' covert attitudes, our paper therefore takes the following two points of departure:

Firstly, in order to fully explore the recorded trend of adolescent male Welsh speakers gravitating towards the use of English in peer-to-peer interactions, we will elicit attitudes regarding the social acceptance of Welsh among L1 speakers. We will do so by employing indirect methods for the elicitation of covert attitudes rather than collecting overt attitudes as in previous literature, thereby also filling a methodological gap apparent in the previous literature (e.g. Coupland et al., 2005; Thomas \& Roberts, 2011; Morris, 2014). As discussed above, eliciting attitudes by direct methods (i.e interview, self-report, questionnaire) provides information on individuals' overt attitudes which may not be representative of or may even conflict with their covert attitudes or inner beliefs (e.g. Baker, 1992). The present study will therefore employ indirect methods with the aim of eliciting covert attitudes.

Secondly, despite this trend male speakers using English in peer-to-peer interactions being reported in disparate geographical regions of Wales, occurring throughout primary, 


\section{Research Questions}

secondary, and tertiary education (Morris, 2010), there is an evident paucity of research on the perceptions of the appropriateness and acceptance of Welsh and English in L1 strongholds, where speaker proficiency is high and there are many opportunities for young speakers to apply Welsh. This study aims to explore the covert attitudes towards Welsh and English held by speakers in an L1 community where Welsh is acquired through the home environment and transmitted through formal schooling. If such groups are to set a standard for L2 speakers as suggested by Thomas et al. (2014), then we need to understand the current connotations among young people towards the role of Welsh and English in contemporary youth culture. With existing research providing overt attitudinal evaluations, and much of that in younger speakers, this paper will tackle the lesser-known L1 adolescent speaker attitudes towards Welsh and English.

As aspects of speaker behaviour (i.e. engaging in language maintenance or loss) can be predicted by speaker belief (i.e. language attitudes) (Allard \& Landry, 1986; 1992), a measure of language attitudes can therefore provide detail regarding the linguistic vitality and potential future trends of a language. As explained above, the perceived connotations of Welsh and English with academic and non-academic domains necessitates a measurement across gender and - therefore - this paper aims to address the following research questions:

(1) Where Welsh is transmitted in the home and community, what covert attitudes are held by L1 native Welsh-English bilingual adolescents towards Welsh and English? (2) Do L1 Welsh adolescents view Welsh and English differently in terms of their relatability 
as a conversational medium of social interaction?

(3) Do female and male adolescents hold different language attitudes towards Welsh and English?

If the observed gender gap is due to the development of a generic trend whereby Welsh is more readily associated with the school environment than with everyday conversation (the "Inverted diglossia" of Price and Tamburelli, 2016), then we would expect to find evidence of this gender gap in L1 heartlands as well, with females rating Welsh more positively than males on traits which are perceived to be connoted with social mobility and academic achievement. In the same vein, we would expect young male speakers to hold less favourable attitudes towards what they perceive to be the more formal, overtly prestigious variety (Labov, 1990; Romaine, 2003). As Welsh becomes increasingly associated with formality and overt prestige, English is likely to begin to be perceived as the language of rebellion against 'the established [linguistic] rules of the adult world' (Rostami, 2012:210) among males. Thus, we would expect that, even in the Welsh heartlands, English would be rated higher on social traits by male informants, while Welsh would be viewed more favourably by females as the language of social and academic concordance.

If, on the other hand, the reported lack of willingness to apply Welsh is mostly due to low-levels of speaker confidence and perceived language competence/ proficiency among users (e.g. Morris, 2014; Thomas, Apolloni \& Lewis, 2014; Thomas \& Roberts, 2011), then we would expect to find no difference in attitudes between the genders in L1 speakers growing up in the heartlands as there will be little to no variation in speaker confidence, since both genders have Welsh as their first language and have access to systematic opportunities to use Welsh in a broad range of conversational domains. Additionally, we would also expect 
our cohort of L1 Welsh adolescent speakers to rate Welsh of equal or greater favourability than English on measures of social traits.

To test these hypotheses and to complement existing qualitative research on the topic,

we use a quantitative method. As this paper provides a follow-up quantitative study from existing qualitative work (e.g. Price and Tamburelli, 2016), we have developed a modification of the matched-guise test, to which we now turn.

\section{Method}

\section{The Matched Guise}

Within socio- and applied- linguistic research, the indirect matched-guise method is favoured as a means of investigating underlying stereotypical prejudices held towards speakers of particular language varieties. In the original conception, Lambert, Hodgson and Fillenbaum (1960) instructed participants in Montreal, Quebec to assess two languages - French and English - on personal attribute scales. The original method entailed one tape-recorded speaker reading several controlled samples of the same passage of text in two distinct language varieties, before asking participants to rate those speech samples. Speech samples are matched for feature, such as speed, volume, timbre, intonation and length thus minimising quality bias. Left to assume all recordings are different speakers, research subjects are then asked to listen to the recorded guises before completing an evaluative questionnaire based on speaker personality and significant social attributes (Mobärg 1989:22). Lambert et al. (1960) found language to be a strong influence upon participant evaluations, with more positive ratings towards English on status and solidarity traits; this was assumed to be indicative of the higher status of English in Quebec at the time of study.

Response data from the Matched Guise is typically grouped along salient dimensions 
- that of solidarity (covertly prestigious) and status (overtly prestigious). Early studies (Lambert, Ainsfeld \& Yeni-Komshian, 1965); Lambert, Frankle \& Tucker, 1966; Lambert, 1967) measured language attitudes across 15 - 18 traits, grouping these traits into three distinct categories (personal integrity, competence and social-attractiveness). Traits relating to dynamism, attractiveness and superiority are taken as representative for eliciting attitudes (Zahn \& Hopper, 1985).

The Matched Guise test is particularly suited to the aims of the present study, as it tacitly measures and records participant reactions by 'tapping-in' to participants' preexisting unconsciously held attitudes towards language varieties. As participants are not aware of what they are being 'tested' on (Garrett, 2010:41), the method is seen as an indirect approach of gaining language attitudes. This technique repeatedly demonstrates different levels of negative rating across different languages which correspond to participants' actualised language preference (e.g. Loureiro-Rodrigues, Bogges \& Goldsmith 2013) and thus provides an informative technique in assessing linguistic vitality. Unlike previous matched-guise studies in Wales which use RP English as a reference point of status (Price, Fluck \& Giles, 1983; Bourhis, Giles \& Tajfel, 1973), the present adaptation provides a contemporary approach suited to the demographic of the study. Furthermore, our adaptation crucially differs from the traditional matched-guise by employing different voice actors with different profiles, as commonly adopted in the verbal guise (see for instance Carrie, 2016; McKenzie and Gilmore, 2017). We include both male and female guises to control for potential evaluative differences driven by gender of guise.

\section{Stimuli}

Two male and two female bilingual Welsh-English speaking voice actors were recruited. All four actors grew up in the North Wales heartland, and have experience of 
1

2

3

4

5

6

7

8

9

Welsh and English in both formal and informal contexts. To accord with young people's aspirational reference points, recruited actors were aged in their twenties, aligning with the notion that young people orientate themselves towards older iconic and idolised figures (Boon \& Lomore, 2001). Voice actors were required to employ two guises in English (Standard Welsh-accented and informal Welsh-accented) and two guises in Welsh (Standard and informal) which remained congruous with the domain of investigation (for identification of 'formal' and 'informal' registers, see Jones, 1998). Guises were oriented to north-west Wales, in-accordance with actors' own true voices and the geographical location in which the research took place.

Recordings were made in a soundproof room using the Marantz PMD-620 voice recorder. Voice actors worked with the primary researcher individually in sessions lasting between 1 - 3 hours. In order to achieve naturalistic, conversational style devoid of 'leading' information, voice actors were prompted to begin speaking by being asked "What did you do over the weekend?", “Be' wnest ti dros y penwythnos?", During these recorded 'chat' sessions, the primary researcher assumed the target variety (i.e. English or Welsh spoken in informal/formal contexts) to aid 'setting the scene'. Voice actors were given refreshments, comfort-breaks and were paid an hourly rate.

As it is imperative that participant reactions are attributed to the language itself, all guises were recorded by native Welsh-English bilinguals and the following guises were produced:

[Table 1: near here]

\footnotetext{
${ }^{2}$ This question was given to voice actors as a prompt. The naturalistic responses were then carefully edited to provide sound clips matched for features of tone, intonation, timbre, speed, volume and content. Study participants were not aware of the question asked to voice actors. For excerpts of the script, please refer to Supporting Information.
} 
During participant evaluations, researchers are required to specify the context in which recordings take place; this negates the risk that participants are guessing contexts for themselves (Campbell-Kibler, 2010; Soukup, 2012). To ensure listeners were certain of the conversational context of recordings, individual ambient backing tracks were produced and added to each recording. Low-domain guises were given an informal environment backing track evocative of a social setting; this included a mixture of indistinguishable low-level music, chatter and mobile device alert sounds. High-domain recordings were given a formal environment backing track evocative of a school setting; this included indistinguishable murmuring, chairs being moved (reminiscent of classroom activity), worksheets being distributed, book-pages turning and writing on paper. The backing tracks were at a consistently lower volume than the speaker recordings in order to keep distraction to a minimum.

\section{Participants}

A total of thirty-five native Welsh-speaking adolescents from Year 10 took part in this study (19 male, 16 female, aged $14-15$ years $^{3}$ ). All participants were currently in secondary education studying at the lower end of Key Stage 4 and were recruited by accessing two separate Year 10 classes. The study took place in a geographical area where Welsh is the dominant language; the school was specifically chosen for having Welsh as the community language with Estyn (2014) reporting 82\% of the school's pupils as coming from Welshspeaking homes - the fourth largest school intake of L1 students in Gwynedd, North Wales. Additionally, the school ranked 'Excellent' for performance and prospects in the 2014 Estyn report, stating that the target school "plans carefully to ensure that there is an increasing use

\footnotetext{
${ }^{3}$ Our sample represents $8.16 \%$ of the overall population based on school type, year group and local authority.
} 
of Welsh". Teachers and school staff are Welsh speaking and the school exhibits Welsh-only signage displayed in classrooms, corridors and communal areas. All study participants had (i) been attending the target secondary school from the age of 11 and (ii) attended primary education in the local area through the medium of Welsh. Selection criteria stipulated participants must come from homes with high exposure to Welsh. All participants included in the final analysis had high-exposure to Welsh, as assessed by a screening questionnaire regarding habitual language exposure in the home. Pupils receiving low-levels of Welsh exposure outside the school environment were excluded from the study $(n=7)$.

\section{Materials}

Two tracks - Track A and Track B - were produced, each featuring the same 17 thirty-second guise recordings with a 20 second pause between recordings. Both Track A and Track B began with the same practice guise, with the following 16 guise arranged to ensure that each speaker's guises were distanced maximally apart. We arranged the recordings so that different versions of each speaker (i.e. each speaker's guise) were featured at maximum distance apart in the final running order. This entailed ordering an individual voice actors' guises at greatest distance from one another. This distancing of guises ensured that participants would not be able to hear same-speaker similarities across guises, and thus remain in the assumption that all guise recordings belonged to different speakers. Both Track A and Track B contained the same test guises but in reverse order to counterbalance for potential tailing effects. In order to provide specific context for listener evaluations, an accompanying image was clearly displayed on a large classroom projector alongside each guise to indicate recording location (i.e. school or social environment). This ensured all participants would perceive a similar conversational setting without deviation for context (Campbell-Kibler, 2010; Soukup, 2012). 
The questionnaire and answer booklet were designed in Welsh and English and piloted with 16 pupils in two after-school clubs in Gwalchmai and Llandonna, Anglesey. The pilots informed necessary alterations, such as increasing soundtrack volume and amending the questionnaire layout. As pupils were provided with the choice of Welsh or English taskbooklet to avoid deviation from standard practice and to avoid drawing attention to the linguistic nature of the task. All participants completed questions on gender, age, past schooling, their own and their family members' home language(s) and three distractor questions. The distractor questions related to out-of-school interests, activities and current participation in clubs. The task booklet (Fig. 4) comprised 16 pages of three five-point Likert scales, one page per guise. During the task, participants were invited to rate each guise on thirty traits (social attributes) on the Likert scale from 'strongly agree' to 'strongly disagree' in a similar format to the Estyn survey (2014) with which students were already familiar. The list of traits was based on existing attitudinal studies (i.e. Echeverria (2005) in the Basque country; Loureiro-Rodriguez, Boggess \& Goldsmith in Galicia, 2013; Woolard in Catalonia, 1989) in addition to traits viewed as socially desirable and relevant to the demographic being investigated; the selected traits represent conflicting attitudes in the context of Welsh maintenance within the school system (Price and Tamburelli, 2016). For instance, findings from Price and Tamburelli (2016) demonstrate that traditional Welsh use is associated with pretentiousness, judgement and a nerdy high-achieving persona. According to their study, the Welsh language contrasts with modernity, good-humour and relatability. All guises were rated on five-point Likert scales in order to mitigate acquiescence bias; inclusion of a midvalue allows for participants to rate neutrality, rather than a 'forced-choice' scale which a could encourage bias (Nadler, Weston and Voyles, 2014). For each trait, each guise was rated 
on 15 pairs of polarised traits ${ }^{4}$, as follows: Rebellious, Conformist, Exciting, Dull, Fashionable, Traditional, Likes a laugh, Boring, Cool, Book-worm, Confident, Awkward, Popular, Lame, Genuine, Pretentious, Natural, Fake, Good-humoured, Goody-two-shoes, Fun, Annoying, Easy-going, Uptight, Relatable, Nerdy, Friendly, Judgmental, Down-to-earth, Smug $^{5}$. In order to avoid priming effects, we specifically avoided using morphological opposites e.g. 'un-natural' in opposition to 'natural', as the negative (i.e. 'unnatural') includes the positive (i.e. 'natural') as well as an instance of prefixiation, which has been shown to lead to priming effects (e.g. Chateau, Knudsen, \& Jared, 2002).

\section{Design}

The independent variables were language of guise (English or Welsh), gender of guise (male or female) and register of guise (high or low). The total matched guise score served as the dependent variable, while participant gender was the independent variable for between subjects. Scores are cumulative and were derived through participants' rating of traits.

Responses were coded from 5 ("strongly agree") to 1 ("strongly disagree") for positive traits and from 1 ("strongly agree") to 5 ("strongly disagree") for negative traits, so that strongly agreeing with the adjective "exciting" would result in a higher score while strongly agreeing with its polar opposite "dull" would result in a lower score.

Participants could score each of the thirty traits on a scale of 1 to 5. Each recording could therefore receive a maximum aggregate score of 150 (30 traits x 5), leading to a potential total score of 300 for each guise (as there were two voice actors representing each guise, as described in the "Stimuli" section). Aggregate scores for each language had a potential maximum score of 600, as each language was scored across two registers and two genders of guise (i.e. $150 \times 2 \times 2=600)$.

\footnotetext{
${ }_{5}^{4}$ Figure 4 demonstrates the arrangement of traits as they appear in the task booklet.

${ }^{5}$ This selection of polarised traits provides an even number of positive and negative traits as semantically matched to each other as possible,
} 


\section{Procedure}

The questionnaire-test booklet was administered during two one-hour classes. Participants were tested by proficient Welsh-English bilingual researchers who introduced themselves and explained the purpose of their visit; the task was explained in relation to 'youth club activity provision' in order to mask the association of the listening task with language attitudes. Participants were told they would hear clips of conversations, after which they were required to rate the recordings on a number of traits.

Participants simultaneously received one English and one Welsh booklet of equal length and were told they could choose whichever booklet they preferred. Participants were then familiarised with all adjectives and the concept of the Likert scale. After having explained and answered any questions participants had regarding adjectives and procedure, all participants were required to complete a trial task. The trial entailed listening to a practice guise three times whilst seeing an image displayed on the classroom projector. During this time, participants were asked to rate the trial guise on the thirty specified separate traits. When all participants had completed the trial task, they were asked to confirm whether they had understood the task, had heard the recordings clearly and could see the displayed image clearly. During this feedback period, participants were visited individually by the teacher and second moderator before testing commenced. Participants were then told to prepare to work individually and quietly for the upcoming task where they would hear a number ${ }^{6}$ of different speaker voices. Guise recordings were played for thirty seconds, with twenty seconds separating each guise to allow for task completion. The primary researcher was able to pause the sound track if necessary.

\footnotetext{
${ }^{6}$ Participants were told to prepare for eighteen different speakers as advised by Loester (2013), although only sixteen guises were played. Loester (2013) reports this device in mitigating participant fatigue and leaving participants feeling positive about the task experience.
} 
The primary researcher and an external moderator worked alongside the class teacher to administer the questionnaire and check progress during the task. One male and one female young white Welsh-British moderator were present, both with experience working with adolescents (for effects of researcher sex, ethnicity and language on response rate and reliability, see Price, Fluck \& Giles, 1983; Webster, 1996; Bellin, Matsuyama \& Schott, 1999; on the importance of local involvement during testing, see Dörnyei 2010: 31; 75).

Correspondence with participants and staff was through the medium of Welsh at all times unless informants requested information through the medium of English. When all participants had finished the experiment and task booklets had been collected, participants were given a full debrief; this included a check to ascertain whether respondents had realized the varying guises were produced by only four voice actors. The results of this check verifies that all participants believed they were rating different speakers (see for example Kristiansen, 2009).

\section{Results}

A 2 (participant gender: male or female) $\times 2$ (language of guise: English or Welsh) $\times$ 2 (register of guise: high or low) x 2 (gender of guise: male or female) mixed-design analysis of variance (ANOVA) was performed on the data, with participant gender as the betweensubjects variable. The results revealed a main effect for three of the four variables: participant gender $F(1,33)=9.088, \mathrm{p}<0.01, \eta_{\mathrm{p}}^{2}=.216$; register of guise $F(1,33)=28.158, \mathrm{p}<0.001, \eta_{\mathrm{p}}{ }^{2}=$ .460 ; and language of guise $F(1,33)=65.183, \mathrm{p}<0.001, \eta_{\mathrm{p}}{ }^{2}=.664$. Figure 1 shows the overall scores for each language, while figure 2 shows how the participants scored the different registers in each language. Figure 3 shows the scores obtained for each language according to participant gender. Table 2 shows the data expressed numerically. 
There was also a two-way interaction between participant gender and language: $F(1,33)=12.222, \mathrm{p}=0.001, \eta_{\mathrm{p}}^{2}=.270$; between gender of guise and language $F(1,33)=$ $5.785, \mathrm{p}=0.022, \eta_{\mathrm{p}}{ }^{2}=.149$, and between gender of guise and register $F(1,33)=17.775, \mathrm{p}<$ $0.001, \eta_{\mathrm{p}}{ }^{2}=.350$. Bonferroni-adjusted post hoc tests showed that the different scores between the two genders are highly statistically significant for Welsh $(\mathrm{p}<0.001)$ but not for English $(\mathrm{p}$ $=.088)$, and that the gender of the guise affects scores for English guises $(\mathrm{p}=0.046)$ but not for Welsh $(\mathrm{p}=0.925)$. Figure 3 shows that while both genders rated English guises more positively than Welsh guises overall, female participants rated Welsh guises significantly more favourably than did male participants.

None of the other interactions were significant $(\mathrm{p}=.199$ or greater).

[Table 2: near here]

[Figure 1: near here]

[Figure 2: near here]

[Figure 3: near here]

\section{Discussion}

We proposed that the reported trend for speakers to abandon the Welsh language beyond the classroom (Baker, 2003; Gathercole \& Thomas, 2009; Thomas \& Roberts, 2011; 
Thomas, Apollonia, \& Lewis, 2014) could be unpacked by investigating speaker covert attitudes towards Welsh and English in home and school contexts. In our first research question, we asked what covert attitudes are held by L1 Welsh-English bilingual adolescents towards Welsh and English; our results have demonstrated that English guises elicit more positive covert attitudes than Welsh overall. Given the pervasive status of English in young peoples' daily lives in connection to new technologies, media and popular culture, it is generally anticipated that some level of favourability towards the dominant language exists within a minority language context. However, when investigating whether our L1 Welsh cohort perceive differences between Welsh and English as a conversational medium, we found that 'social' guises were rated more favourably than 'school' guises; this is not surprising given that informal varieties often accrue higher ratings on social and solidarity traits (see Echeverria, 2005), when specifically in a solidarity-stressing context (i.e. school vs home). Consistent with the literature on attitudes towards informal and formal varieties (Bourhis, Giles and Tajfel, 1973; Bellamy, 2010; Hogg et al 1984; Stewart et al, 1985; Trudgill 2000), we found that informal register guises do attract more positive responses on socially desirable qualities than formal register guises. However, as demonstrated in Figure 2, both social and school registers of English were rated most favourably overall by both genders, regardless of context. Therefore, while low registers are consistently rated more favourably than high registers within each language, English is rated higher than Welsh overall, with favourability towards high-register English being higher than that attributed to low-register Welsh. We further hypothesised that, if the previously reported gender gap is due to the development of a generic trend whereby Welsh is more readily associated with the school environment than with everyday conversation (the "Inverted diglossia" of Price and Tamburelli, 2016), then we would see different language attitudes towards Welsh and English between male and female participants. In line with the concept of inverted diglossia, our 
results demonstrate a gender gap between males and females within an L1 community context. This is evident in the ratings attributed towards Welsh and English guises, with male participants rating Welsh less positively than did female participants. This result lends empirical support to the view that Welsh is increasingly perceived as a language of school and officialdom, with English fulfilling the role of the language of leisure.

\section{Despite the fact that causative factors of Welsh language disfavour among speakers} previously reported in the literature (i.e low-levels of confidence, exposure to language, lacking opportunities of use) do not apply to our L1 heartland cohort, Welsh is still being perceived as less socially appropriate among young people - particularly males - among active L1 speakers. Our results show that lacking opportunity to use Welsh is not the only issue for consideration in assessing the linguistic behaviour of Welsh adolescents. Our study shows that young speakers turning away from Welsh cannot be entirely explained by lack of speakers' confidence or lack of opportunity for use, as all of our participants were WelshEnglish L1 bilinguals with high native fluency in Welsh. Contrary to presently accepted explanations, this phenomenon cannot be fully explained by low-levels of confidence in speakers or that speakers resort to English as the language of inclusivity (as reasoned by Thomas \& Roberts, 2011). Our study cohort were of high native fluency with Welsh as the home language, with reportedly high levels of confidence and oral performance in Welsh academically (see Estyn, 2014).

\section{We further understand that confidence and lacking opportunity cannot wholly explain} speakers turning away from Welsh, as if this were the case, we would have found no difference in attitudes between males and females growing up in the heartlands, since both genders have Welsh as an L1 and systematic opportunities to use Welsh in a broad range of 
conversational domains. Contrastively, Welsh is significantly disfavoured as a social status symbol most befitting youth culture among males. If this were simply explained by English as a popular global language of youth culture, then female participants would be expected to display the same tendencies. Additionally, as Estyn (2014) reported no significant gender gap between the academic achievement of KS3 and KS4 boys and girls in the target school, we suggest that our results demonstrate English as more befitting an emblem of youth culture among Welsh L1 males.

Our study demonstrates Welsh being perceived as a language of formality and overt prestige, thus being rejected as a conversational medium among males both inside and beyond the classroom (as reported in the wider literature). Our results accord with wider sociolinguistic gender research, which consistently demonstrates that female speakers converge towards overtly prestigious speech varieties (i.e. Eckert, 1989, 1990, 1998) and male speakers reject prestige forms 'from above' (Labov, 1990; Romaine, 2003). Females generally demonstrate more positive attitudes towards standard varieties, employing more standard forms in signaling linguistic social status (Milroy, 1987; Trudgill, 1972); females are also 'less anchored' vernacular speakers of their community (Preston, 2016) and more likely to converge towards prestigious forms. Female speakers also tend to be more active users of the $\mathrm{H}$ variety; previous studies have found female speakers to be more active users of Welsh than their male peers (Hodges, 2011; Thomas and Roberts, 2011) and found connotations of Welsh with formality and academic achievement among males (Price and Tamburelli, 2016). Indeed, it is well known that males habitually diverge from the formal language, behaving in direct opposition to the established status quo. Young male speakers are known to risk social exclusion by their peer group by use of the superordinate speech style (see Labov, 1972) and therefore particularly averse to adopting what is considered the overtly prestigious and formal 
variety. A sort of sociolinguistic 'rebellion' is thus expressed in attitudes divergent from the superordinate variety and convergent towards the covertly prestigious English language in order to gain, or possibly retain, in-group solidarity with male peers. This is in line with the work of Echeverria (2005) which found that the variety most highly regarded by adolescents for social use was the variety that was less prominent in the school curriculum (i.e. vernacular Basque). If this interpretation is correct, the overt policies of the immersive Welsh schooling environment may be implicitly and unwittingly stimulating the association of English as the language of 'rebellion and refuge' (Price and Tamburelli, 2016). Our findings are therefore consistent with the hypothesis advanced in this paper, namely that the established gender gap is at least partly due to a generic trend of "Inverted diglossia" (Prince and Tamburelli, 2016) whereby the increased association of Welsh with the school environment is creating an essentially diglossic opposition with English as the language of everyday conversation.

In addition, we suggest that such top-down attitudes influence expectations for success, and thus female participants of this study tend to rate Welsh more favourably in accordance with the associative opportunities for Welsh-medium socio-economic advancement in contemporary Wales today. As Welsh guises are being perceived by female participants in accordance with formality, hard-work, schooling and social aspirations, those same Welsh guises appear to be incompatible with the anti-schoolwork construction of masculinity (Court, 2001: 34). On this view, It is therefore unsurprising that males tend to turn towards English as a medium of social communication, and thus prefer English guises insofar as they represent the rejection of authority among males (for reinforcement of peergroup identities, see Paulini, Maher, \& Murty, 2014 ; see Esc.. 2005; Woolard, 2003: 86). We suggest thus explaining the high levels of covert prestige afforded to English guises could be partly due to English being recognised as an emblem of adolescent culture among Welsh male adolescents in the heartlands. 
Finally, it must be noted that such favourability attributed by our participants towards English is in stark contrast with reports from the literature (i.e. Laugharne, 2007; Morris, 2014) which state L1 speaker language attitudes to be more favourable towards Welsh. While these previous reports elicited overt attitudes (see earlier discussion in the literature review), our findings provide a candid report on speakers' less-consciously held covert beliefs, with potentially more informative evidence on language behaviour. Unlike previous studies, our L1 Welsh adolescents view English as more favourable than Welsh on measures of social attractiveness within youth culture. It is therefore unsurprising that our results diverge from those reported in previous literature, due to the direct manner of their methodologies; recalling Baker (1992), the use of direct methods elicit an outer view, while indirect methods elicit accurate representations of participant attitudes. If, as some have argued (e.g. De Houwer, 1999), it is primarily covert 'inner' held beliefs which lie at the basis of real-time language behaviour and can be understood as determinants of language uptake (see McGuire, 1974; 1976), then our study contributes a vital step forward in quantitatively eliciting covert attitudes as a measure of minority language vitality.

\section{Conclusions}

This study provides quantitative evidence that attitudes are an important issue at L1 community level as well as the L2 communities already observed in previous literature (Hodges, 2011; Price \& Tamburelli, 2016; Thomas et al, 2012), and that opportunity to use Welsh and language confidence are not as central to explaining reported trends of speakers turning away from Welsh as previously thought.

Along with our findings, the cohort demonstrate high levels of confidence and oral 
performance, with no obvious gender gap in academic achievement (Estyn, 2014). While we acknowledge that future attitude research should directly measure language aptitude, all pupils in the present study had high exposure to Welsh, and thus little variance regarding confidence and little variance in aptitudes; this suggests that 'confidence' is not a major driving force behind male speakers' disfavour of Welsh as previously suggested (see for example, Thomas and Roberts, 2011). Instead, our study indicates that English is perceived as more relatable medium to young male adolescents than Welsh for use in informal social domains. The current study helps to explain the phenomenon whereby Welsh-medium pupils are reportedly using Welsh for in-class exercises yet conducting wider community and peerto-peer social interaction through English (see Cenoz 2008 for similar findings in other minority languages). These findings provide a crucial link in understanding the perceived image of Welsh and English guises in the eyes of young L1 Welsh speakers, thus giving explanatory power behind both L1 and L2 speakers' 'reluctance' to apply the language in informal communicative domains (Thomas and Roberts, 2011). The extent to which this compartmentalisation - Welsh as the middle-class socially advancing language, English as the elsewhere informal language - is evident in young speakers' perceptions today has been explored throughout this study.

In terms of practical implications, our study indicates that, if Welsh is to thrive as a medium of communication among young people, there is a need for (i) Welsh to become more relevant to youth culture (for example within contemporary music and media domains). Also, (ii) a greater focus on Welsh male role-models beyond the classroom environment and into the social domains, both across an advanced case of revitalisation and also across the breadth of the heartland stronghold. While the demographic of this study are Welsh-English bilinguals, the attitudes uncovered by this study - combined with previous reports in the literature relating to male speakers' preference of English - suggest that we have a covert 
issue which needs addressing. In order to address and foster positive attitudes towards Welsh

language among young people, feasible interventions may include the introduction of

contemporary arts within the classroom environment, thus relating the language to

intrinsically motivated activities. Such activity could capitalise on the new curriculum

coming into force in Wales in 2020 by linking with existing vocational schemes, such as the

Lead Creative Schools scheme (Welsh Government, 2016).

References

Allard, R., \& Landry, R. (1986). Subjective ethnolinguistic vitality viewed as a belief system. Journal of Multilingual \& Multicultural Development, 7, 1-12. Doi:

$10.1080 / 01434632.1986 .9994226$

Baker, C. (2003) Language Planning: A Grounded Approach. In J.M Dewaele, A. Housen, \& L. Wei Bilingualism: Beyond Basic Principles: Festschrift in Honour of Hugo Baetens Beardsmore. (pp. 88 - 111) Clevedon: Multilingual Matters.

Bellamy, J. (2010) Language Attitudes in England and Austria: Comparing Reactions towards High and Low-Prestige varieties in Manchester and Vienna. (Unpublished doctoral thesis) Faculty of Languages, Linguistics and Cultures, University of Manchester. 
Bilaniuk, L. (2003) Gender, language attitudes, and language status in Ukraine. Language in Society, 32, 47-78. Doi: 10.1017/S0047404503321037

Boon, S. D., \& Lomore, C. D. (2001). Admirer-celebrity relationships among young adults. Human Communication Research, 27, 432-465. Doi: 10.1111/j.1468-2958.2001.tb00788.x

Bourhis, R. Y., Giles, H., \& Tajfel, H. (1973). Language as a determinant of Welsh identity. European Journal of Social Psychology, 3, 447-460.Doi: 10.1002/ejsp.2420030407

Campbell-Kibler, K. (2010). The effect of speaker information on attitudes toward (ING). Journal of Language and Social Psychology, 29, 214-223. Doi: 10.1177/0261927X09359527

Carrie, Erin (2016). 'British is professional, American is urban': attitudes towards English reference accents in Spain. International Journal of Applied Linguistics, 27(2), 427-447. Doi: 10.1111/ijal.12139

Cenoz, J. (2008). Teaching Through Basque: Achievements and challenges. Clevedon: Multilingual Matters.

Chateau, D., Knudsen, E. V., \& Jared, D. (2002). Masked priming of prefixes and the influence of spelling-meaning consistency. Brain and Language, 81, 587-600. Doi: 10.10006/brln.2001.2549

Cormack, M. (2007). The Media and Language Maintenance. In M. Cormack and N. Hourigan (Eds.) Minority Language Media: Concepts, Critiques and Case Studies (pp. 52- 
68). Clevedon: Multilingual Matters.

Coupland N., Bishop, H., Williams, A., Evans, B \& Garrett, P. (2005) Affiliation, Engagement, Language Use and Vitality: Secondary School Students' Subjective Orientations to Welsh and Welshness, International Journal of Bilingual Education and Bilingualism, 8, 1-24. Doi: 10.1080/jBEB.v8.i1.pg1

Court, K. (2001). Why Are Boys Opting Out?: A Study of Situated Masculinities and Foreign Language Learning. Retrieved from: www.ling.lancs.ac.uk/groups/crile/crile57/court.pdf

De Houwer, A (1999) Environmental factors in early bilingual development in Bilingualism and Migration. In G. Extra \& L. Verhoeven (Eds.) Bilingualism and Migration: Studies on Language Acquisition, (pp. 75-95), New York: Mouton de Gruyter.

Dörnyei, Z. (2001). Teaching and Researching Motivation. Harlow: Pearson Education

Dörnyei, Z. (2010) Researching motivation: From integrativeness to the ideal L2 self. In S Hunstone \& D Oakey (Eds.) Introducing applied linguistics: Concepts and skills (pp. 74-83), London: Routledge.

Echeverria, B. (2005) Language Attitudes in San Sebastian: The Basque Vernacular as Challenge to Spanish Language Hegemony, Journal of Multilingual and Multicultural Development, 26, 249-264. Doi: 10.1080/01434630508668407

Eckert, P. (1989). The whole woman: Sex and gender differences in variation. Language 
variation and change, 1, 245-267. Doi: https://doi.org/10.1017/S095439450000017X

Eckert, P. (1990). Cooperative competition in adolescent "girl talk". Discourse Processes, 13, 91-122. doi: 10.1080/01638539009544748

Eckert, P. (1998). Gender and sociolinguistic variation. Language and gender: a reader (pp. 64-75). Oxford: Blackwell.

Estyn, Her Majesty’s Inspectorate for Education and Training in Wales (2014) School Inspection Report. Cardiff: Estyn. Retrieved from https://www.estyn.gov.wales/provider/6614031

Fasold, R (1984). The Sociolinguistics of Society. Oxford: Blackwell.

Garrett, P. (2010). Attitudes to language. Cambridge University Press.

Gathercole, V. C. M. (2002). Grammatical gender in bilingual and monolingual children: A Spanish morphosyntactic distinction. In D. Kimbrough Oller \& R. E. Eilers (Eds.) Language and literacy in bilingual children, (pp. 207-219), Clevedon: Multilingual Matters.

\author{
Gathercole, V. C. M (2007). Miami and North Wales, so far and yet so near: A constructivist \\ account of morphosyntactic development in bilingual children. International Journal of \\ Bilingual Education and Bilingualism, 10, 224-247. Doi: 10.2167/ \\ beb442.0
}


Gathercole, V. C. M., \& Thomas, E. M. (2009). Bilingual first-language development:

Dominant language takeover, threatened minority language take-up. Bilingualism: Language and Cognition, 12, 213-237. Doi: 10.1017/S1366728909004015

Gruffudd, H. (2000). Planning for the use of Welsh by young people. Language revitalization: Policy and planning in Wales. In C. H. Williams (Ed.), Language revitalization: Policy and planning in Wales. (pp. 173-207). Cardiff: University of Wales Press.

Harmer, J. (1991). The Practice of English Language. Teaching. London: Longman Hickey, T. M. (2007). Children's language networks in minority language immersion: What goes in may not come out. Language and Education, 21, 46-65. Doi: 10.2167/le617.0

Hodges, R. (2009). Welsh language use among young people in the Rhymney valley. In Contemporary Wales (pp. 16-35). Cardiff: University of Wales Press.

Hodges, R. (2011). Towards the light/Tua'r Goleuni? Welsh-medium education for the nonWelsh speaking in south-Wales: A parent's choice. In International conference of minority languages Tartu conference proceedings, 303-314. Estonia: Esuka-Jeful.

Hodges, R. (2012). Welsh-medium education and parental incentives - the case of the Rhymni Valley, Caerffili. International Journal of Bilingual Education and Bilingualism, 15, 355-373. Doi: 10.1080/13670050.2011.636796 
Hogg, Michael A., Joyce, Nicholas \& Dominic Abrams (1984). Diglossia in Switzerland? A social identity analysis of speaker evaluations. Journal of Language and Social Psychology, 3, 185-196. Doi: 10.1177/0261927X8400300302

Jones, B. M. (1990) Variation in the Use of Pronouns in Verbnoun Phrases and Genitive Noun Phrases in Child Language. In M, J, Ball; J, Fife, E, Poppe \& J, Rowland (Eds.) Celtic Linguistics, Ieithyddiaeth Celtaidd (pp. 53 - 76), John Benjamins: Amsterdam.

Jones, M. C. (1998). Language obsolescence and revitalization: Linguistic change in two sociolinguistically contrasting Welsh communities. Oxford University Press.

Jones, D. V., \& Martin-Jones, M. (2004). Bilingual education and language revitalization in Wales: Past achievements and current issues. In W. Tollefson \& A. Tsui (Ed.s), Medium of instruction policies: Which agenda? Whose agenda? (pp. 43-70). New Jersey, NJ: Lawrence Erlbaum Associates.

Kenesei, I. (2009). Minority languages in Hungary. In G. Stickel (Ed.), National, regional and minority languages in Europe: Contributions to the annual conference 2009 of EFNIL in Dublin. Duisburg papers on research in language and culture, 63-72. Frankfurt: Peter Lang Press.

Kristiansen, T., Harwood, J., \& Giles, H. (1991). Ethnolinguistic vitality in the Danish capital of America'. Journal of Multilingual \& Multicultural Development, 12, 421-448. Doi: $10.1080 / 01434632.1991 .9994474$ 
Kristiansen, T. (2009) The macro-level social meanings of late-modern Danish accents. Acta Linguistica Hafniensia International Journal of Linguistics, 41, 167-192. Doi:

$10.1080 / 03740460903364219$

Labov, W. (1972). Some principles of linguistic methodology. Language in society, 1, $97-$ 120. Doi: $10.1017 / \mathrm{S} 0047404500006576$

Labov, W. (1990). The intersection of sex and social class in the course of linguistic change. Language Variation and Change, 2, 205-254. doi: 10.1017/S0954394500000338

Lambert, W. E., Hodgson, R. C., Gardner, R. C., \& Fillenbaum, S. (1960). Evaluational reactions to spoken languages. The Journal of Abnormal and Social Psychology, 60, 44. Doi: $10.1037 / \mathrm{h} 0044430$

Lambert, W. E., Anisfeld, M., \& Yeni-Komshian, G. (1965). Evaluation reactions of Jewish and Arab adolescents to dialect and language variations. Journal of Personality and Social Psychology, 2, 84. doi: : 10.1037/h0022088

Lambert, W. E., Frankle, H., \& Tucker, G. R. (1966). Judging personality throught speech: a French-Canadian example. Journal of Communication, 16, 305-321. Doi: 10.1111/j.14602466.1966.tb00044.x

Lambert, W. E. (1967). A social psychology of bilingualism. Journal of social issues, 23, 91109. Doi: 10.1111/j.1540-4560.1967.tb00578.x 
Landry, R., \& Allard, R. (1992). Ethnolinguistic vitality and the bilingual development of minority and majority group students. In W. Fase, K. Jaspaert, S. Kroon (Eds.), Maintenance and Loss of Minority Languages: Studies in Bilingualism 1 (pp.223-251) Amsterdam: John Benjamins.

Laugharne, J (2007). Language Use and Language Attitudes in Wales. In D. Lasagabaster, A, Huguet. Multilingualism in European Bilingual Contexts: Language Use and Attitudes. (pp. 208 - 233) Clevedon: Multilingual Matters.

Loester, B (2013). A new awareness or dangerous nationalist tendencies? An assessment and evaluation of recent measures in Bavaria and implications further afield. [Conference Paper given at Contested Languages in the Old World, Bangor University]. Retrieved from: https://www.researchgate.net/publication/279289148_A_new_awareness_or_dangerous_nati onalist_tendencies_An_assessment_and_evaluation_of_recent_measures_in_Bavaria_and_im plications_further_afield.

Loureiro-Rodriguez, V., Boggess, M. M., \& Goldsmith, A. (2013). Language attitudes in Galicia: using the matched-guise test among high school students. Journal of Multilingual and Multicultural Development, 34, 136-153. Doi: 10.1080/01434632.2012.729591

Lyon, J. Ellis, N. (1991) Parental attitudes towards the welsh language. Journal of Multilingual and Multicultural Development, 12. Doi:

http://dx.doi.org/10.1080/01434632.1991.9994461

Maegaard, M. (2005). Language attitudes, norm and gender: A presentation of the method 
and results from a language attitude study. Acta Linguistica Hafniensia International Journal of Linguistics 37, 55-80. Doi: 10.1080/03740463.2005.10416083

Maegaard, M. (2010). Linguistic practice and stereotypes among Copenhagen adolescents. In P. Quist, B. A Svendsen (Eds.) Multilingual urban Scandinavia: New linguistic practices (pp. 189-206). Clevedon: Multilingual Matters.

May, S. (2000) Accommodating and Resisting Minority Language Policy: The Case of Wales, International Journal of Bilingual Education and Bilingualism, 3:2, 101-128. Doi: $10.1080 / 13670050008667702$

McGuire, W. J. (1974). Psychological motives and communication gratification. In J. G. Blumler., E. K (Eds.) The uses of mass communications: Current perspectives on gratifications research, (pp. 167-196). CA: Sage.

McGuire, W. J. (1976). Some internal psychological factors influencing consumer choice. Journal of Consumer research, 2, 302-319. Doi: 10.1086/208643

McKenzie, Robert M. and Gilmore, Alexander (2017). "The people who are out of 'right' English": Japanese university students' social evaluations of English language diversity and the internationalisation of Japanese higher education. International Journal of Applied Linguistics, 27 (1), 152-175. Doi: 10.1111/ijal.12110

Milroy, L. (1987). Language and social networks. Wiley-Blackwell. 
Morris, D. (2010). Young people and their use of the welsh language. In D. Morris (Ed.), Welsh in the 21st century, (pp. 80-98). Cardiff: University of Wales Press.

Morris, J. (2014). The influence of social factors on minority language engagement amongst young people: an investigation of Welsh-English bilinguals in North Wales. International Journal of the Sociology of Language, 65-89. Doi: 10.1515/ijs1-2014-0027

Nadler, J. T., Weston, R., Voyles, E. C. (2014) Stuck in the Middle: The Use and Interpretation of Mid-Points in Likert Questionnaires. The Journal of General Psychology. Vol 124. Is. 2. Doi: 10.1080/00221309.2014.994590

Ó Duibhir, P (2009) A conmparison of Irish immersion students' attitudes and motivation to Irish in the Republic of Ireland and Northern Ireland. Proceedings of the BAAL Annual Conference (Newcastle University), pp. 113-6.

Ó Riagáin, P., Williams, G. \& Moreno, X. (2008). Young people and minority languages: Language use outside the classroom. Dublin: Centre for Language and Communications Studies, Trinity College.

Paulini, M., Maher, M. L., \& Murty, P. (2014). Motivating participation in online innovation communities. International Journal of Web Based Communities, 10, 94-114. doi:

10.1504/IJWBC.2014.058388

Preston, D. (2016) Where to find attitudes (and what to do with them): Origins, triggers, and pathways. [Plenary session conference paper from Sociolinguistic Symposium 21, Murcia, 
Spain].

Price, A. R. \& Tamburelli, M. (2016): Minority language abandonment in Welsh-medium educated L2 male adolescents: classroom, not chatroom. Language, Culture and Curriculum. 29, 189-206. doi: 10.1080/07908318.2015.1136323

Price, S., Fluck, M. \& Giles, H. (1983). The effects of language of testing on bilingual preadolescents' attitudes towards welsh and varieties of English. Journal of Multilingual \& Multicultural Development, 4, 149-161. doi: 10.1080/01434632.1983.9994108

Rhys, M. \& E.M. Thomas. (2013). Bilingual Welsh-English Children's Acquisition of Vocabulary and Reading: Implications for Bilingual Education. International Journal of Bilingual Education and Bilingualism, 16, 633-656. doi:

$10.1080 / 13670050.2012 .706248$

Romaine, S. (2003). Variation. In C. J. Doughty \& M. H. Long (Eds.) The handbook of second language acquisition, (pp. 410-435). Oxford: Blackwell Publishing.

Rostami, M. S. (2012). A model for the evaluation of translations: with an emphasis on the stylistic features. International Journal of Linguistics, 4, 55-72. doi:

https://doi.org/10.5296/ijl.v4i2.1608

Ruffino, G. (2006). L'indialetto ha la faccia scura: giudizi e pregiudizi linguistici dei bambini italiani. Sellerio Ed. 
Schiffman, H. (1996) Linguistic culture and language policy. London: Routledge.

Sophocleous, A. (2011) Two Languages in the Classroom: The Inconsistency Between National and Local Objectives of Formal Education in Cyprus. Journal of Language, Identity and Education. 10, 266-281. doi: 10.1080/15348458.2011.598129

Soukup, B. (2012). Current issues in the social psychological study of 'language attitudes': constructionism, context, and the attitude-behavior link. Language and Linguistics Compass, 6, 212-224. doi: 10.1002/lnc3.332

Stewart, M.A, Ryan, E.B. \& Giles, H (1985). Accent and social class effects on status and solidarity evaluations. Personality and Social Psychology Bulletin 11, 98-105. doi: $10.1177 / 0146167285111009$

Taylor, A. (2000). “Boy-free zone?” Language Learning Journal, 21, 3-7. doi: $10.1080 / 09571730085200031$

Thomas, E. M., \& Roberts, D. B. (2011). Exploring bilinguals' social use of language inside and out of the minority language classroom. Language and Education, 25, 89-108. doi: $10.1080 / 09500782.2010 .544743$

Thomas, E. M., Lewis, W. G., \& Apolloni, D. (2012). Variation in language choice in extended speech in primary schools in Wales: Implications for teacher education. Language and Education. 26, 245-261. doi: 10.1080/09500782.2011.640433 
Thomas, E. M., Apollonia, D., \& Lewis, G. (2014) The learner's voice: exploring bilingual children's selective language use and perceptions of minority language competence.

Language and Education. 28. 340-361. doi:

$10.1080 / 09500782.2013 .870195$

Trudgill, P. (1972). Sex, covert prestige and linguistic change in the urban British English of Norwich. Language in society, 1, 179-195. doi: 10.1017/S0047404500000488

Trudgill, P. (2000). Sociolinguistics. An Introduction to Language and Society. London: Penguin.

Wang, L., \& Ladegaard, H. J. (2008). Language attitudes and gender in China: Perceptions and reported use of Putonghua and Cantonese in the southern province of Guangdong. Language Awareness, 17, 57-77. doi: 10.2167/1a425.0

Webster, C. (1996). Hispanic and Anglo interviewer and respondent ethnicity and gender: the impact on survey response quality. Journal of Marketing Research, 62-72. doi: $10.2307 / 3152013$

Welsh Government (2016) Retrieved from: http:/gov.wales/topics/culture-tourismsport/arts/creative-learning-through-the-arts/?lang=en

Welsh Language Act, Ch. 38. (1993). Retrieved from: http://www.legislation.gov.uk/ukpga/1993/38/ 
pdfs/ukpga_19930038_en.pdf

Welsh Language Act, Ch. 66. (1967). Retrieved from:

http://www.legislation.gov.uk/ukpga/1967/66/

pdfs/ukpga_19670066_en.pdf

Wieland, K. (2009). Young people's language in Barcelona and its representation in the mass media. [Unpublished article] Retrieved from:

www.gencat.cat/llengua/noves/noves/hm09hivern/docs/a_wieland.pdf

Williams, C. H. (1992) Agencies of language reproduction in Celtic societies. In W. Fase, K. Jaspaert, S. Kroon (Eds.), Maintenance and Loss of Minority Languages: Studies in Bilingualism 1 (pp. 307-330). John Benjamins: Amsterdam.

Woolard, K. A. (1989). Double talk: Bilingualism and the politics of ethnicity in Catalonia. Stanford: California.

Woolard, K. A., \& Gahng, T. J. (1990). Changing language policies and attitudes in autonomous Catalonia. Language in Society, 19, 311-330. doi: 10.1017/S0047404500014536

Woolard, K. A. (2003). We don't speak Catalan because we are marginalized: Ethnic and class meanings of language in Barcelona. In R. K Blot (Ed.) Language and social identity, (pp. 85-104). Praeger: London.

Bellin, W., Matsuyama, A., \& Schott, G. (1999). Teaching a “dead” language, teaching 


\author{
through a "dead" language: conflict and consensus during language revitalisation. In Eusko \\ Jauralitza and Gobierno Basco, Proceedings of the Seventh International Minority \\ Languages Conference, Bilbao, Spain.
}

Zahn, C. J., \& Hopper, R. (1985). Measuring language attitudes: The speech evaluation instrument. Journal of language and social psychology, 4, 113-123. doi:

$10.1177 / 0261927 X 8500400203$

[Figure 4: near here] 
Table 1

\begin{tabular}{|c|c|c|c|}
\hline & \multicolumn{2}{|c|}{$\begin{array}{l}\text { Low domain } \\
\text { register }\end{array}$} & High domain register \\
\hline Welsh & Male & Female & Male Female \\
\hline English & Male & Female & Male Female \\
\hline
\end{tabular}

10

11

12

13

14

15

16

17

18

19

20

21

22

23

24

25

26

27

28

29

30

31

32

33

34

35

36

37

38

39

40

41

42

43

44

45

46

47

48

49

50

51

52

53

54

55

56

57

58

59

60 
Table 2: Mean scores (and standard deviations) on Welsh and English guises for male ( $\mathrm{N}=$ 19) and female $(\mathrm{N}=16)$ participants

\section{English}

High Register guise Low register guise

\begin{tabular}{lcc}
\hline \hline Males & $180.71(20.00)$ & $191.44(17.43)$ \\
Females & $185.12(26.02)$ & $199.43(18.67)$
\end{tabular}

Welsh

High Register guise Low register guise

\begin{tabular}{lcc}
\hline \hline Males & $153.73(22.88)$ & $161.71(20.82)$ \\
Females & $173.34(21.12)$ & $188.78(25.90)$
\end{tabular}




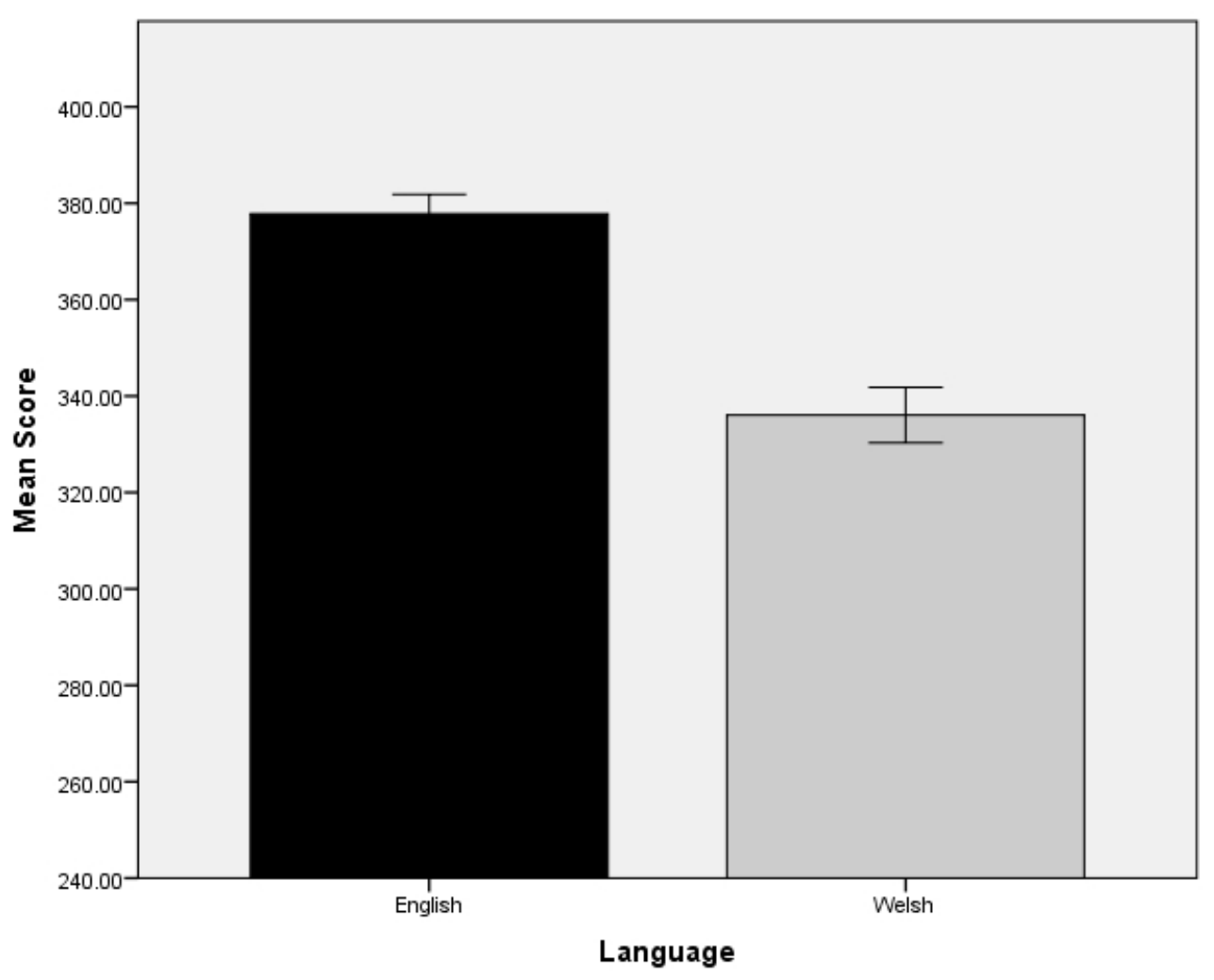

Figure 1: Total matched guise scores for each language

$165 \times 132 \mathrm{~mm}(96 \times 96 \mathrm{DPI})$ 


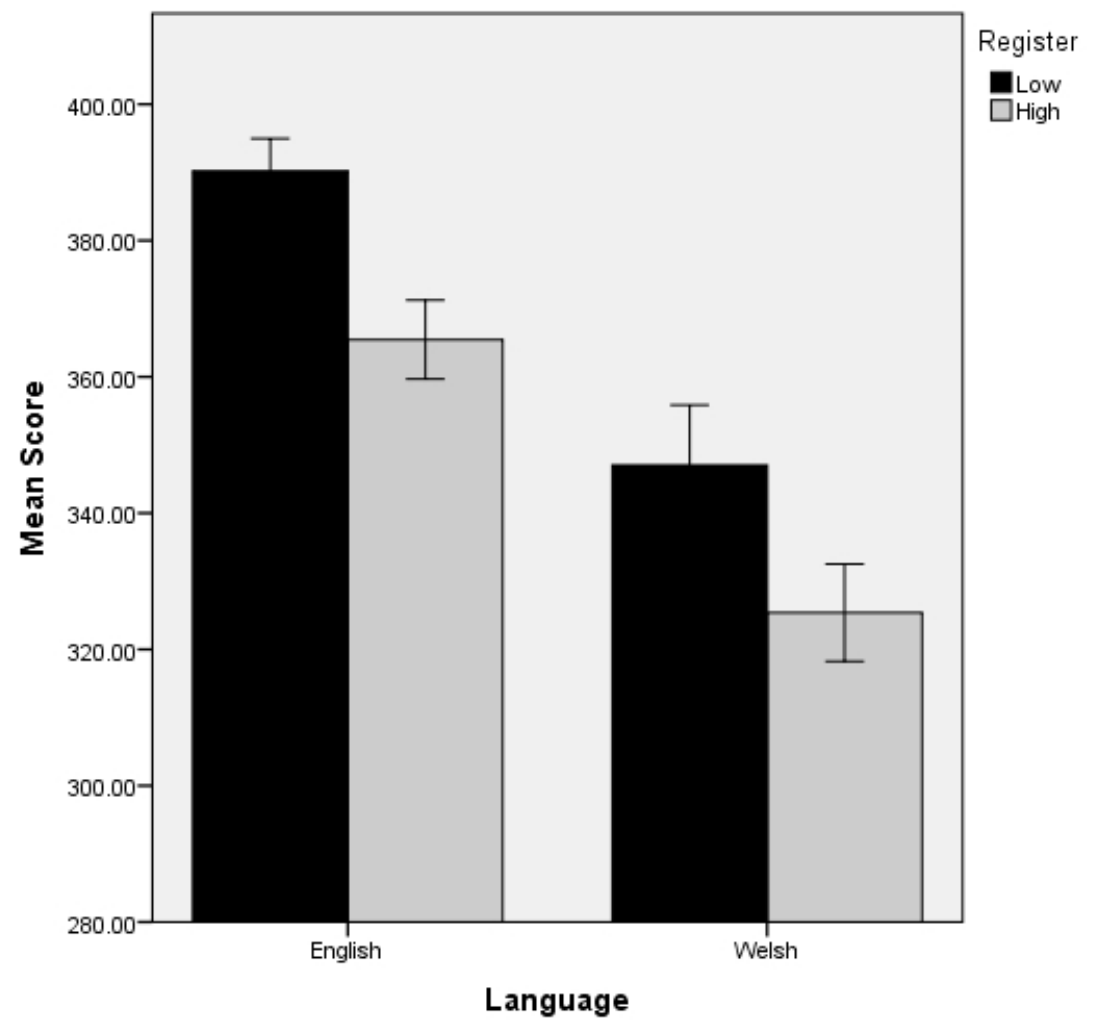

Figure 2: Matched guise scores for each language by register of guise $165 \times 132 \mathrm{~mm}(96 \times 96 \mathrm{DPI})$ 


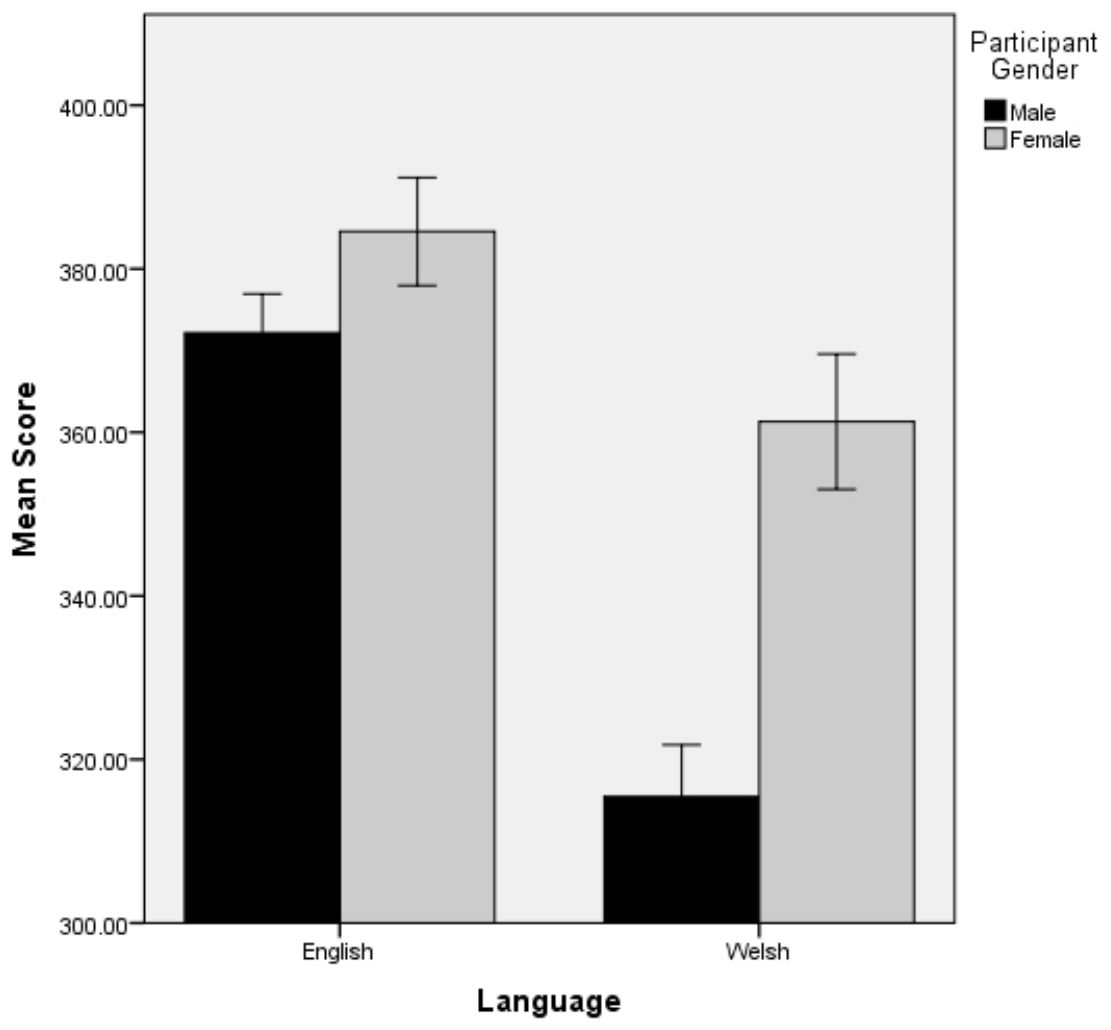

Figure 3: Scores for Welsh and English guises by participant gender $165 \times 132 \mathrm{~mm}(96 \times 96 \mathrm{DPI})$ 
? How much do you agree/ disagree that the speaker seems:

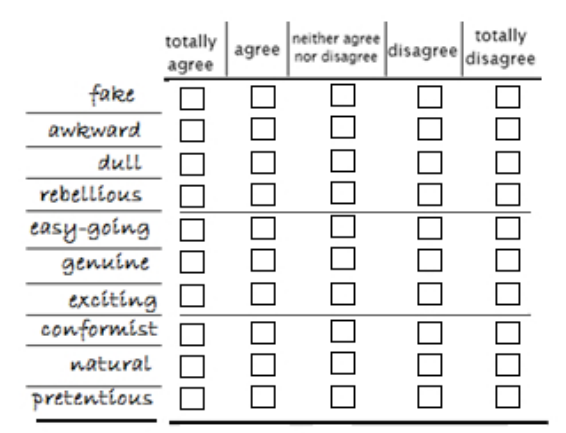

speaker

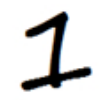

? Where do you think this conversation is taking place?

? Would you socialise with this person? Yes / No

Figure 4: Task booklet example page in English $183 \times 233 \mathrm{~mm}(96 \times 96 \mathrm{DPI})$ 